\title{
RELAÇÃO CIDADE-CAMPO: atividade se costumes rurais sob a rede de alta tensão em Campina Grande-PB ${ }^{1}$
}

\section{CITY-COUNTRYSIDE RELATIONSHIP: activities and rural customs under a high voltage network at Campina Grande-PB}

\author{
Sonale Vasconcelos de Souza \\ Mestre em Geografia \\ UFP \\ sonalegeo@gmail.com
}

\section{Resumo:}

Este artigo teve como objetivo evidenciar a existência de atividades rurais dentro do perímetro urbano de Campina Grande e mostrar a importância dessas atividades no cotidiano de quem às pratica. Desse modo, o intuito aqui foi compreender como as atividades rurais são mantidas ou recriadas em áreas não edificadas na cidade. Para a análise selecionamos como recorte espacial a área sob a rede de alta tensão e dentre as atividades rurais existentes escolhemos as criações de gado, por serem predominantes. Além disso, priorizamos como procedimentos metodológicos: os trabalhos de campo, as observações e as entrevistas. Por fim, verificou-se que as práticas rurais na cidade consistem em "táticas" encontradas pelas pessoas, geralmente migrantes, para viverem na cidade, a qual é concebida a priori para a realização de atividades secundárias e terciárias.Além disso, a permanência das atividades e dos costumes rurais na cidade se dá não apenas devido a uma necessidade econômica, mas, sobretudo, em função do desejo e do prazer de viver de maneira semelhante ao modo de vida rural.

Palavras-chave: cidade, modo de vida rural, subespaços rurais, criação de gado, apropriação.

\begin{abstract}
:
This article aimed at evidencing the existence of rural activities inside the urban perimeter of Campina Grande and showing the importance of these activities in the daily life of those who practice them. Thus, it had the purpose of understanding how the rural activities are maintained and recreated in non-inhabited areas in the city. For the analysis we selected as a space the area under a high voltage network and among the existing rural activities we chose the cattle breeding, as they are predominant. Besides, we prioritized as methodological procedures: the field work, the observations and the interviews. Lastly, it was verified that the rural practices in the city consisted of "tactics" found by the people, usually migrants, in order to live in the city, something which is conceived a priori for the performance of secondary and tertiary activities. Furthermore, the permanence of the activities and the rural customs in the city occurs not only due to an economic need, but, above all, in function of the desire and the pleasure of living in a way similar to that of the rural life.
\end{abstract}

Keywords: city, way of rural life, rural sub-spaces, cattle breeding, appropriation. 


\section{Introdução}

A relação cidade-campo, bem como a divisão do trabalho que distingue essas duas espacialidades, ao longo do tempo tem se tornado complexa e contraditória. Desde a divisão do trabalho que se dá no modo de produção capitalista, cidade e campo se separam, já que o trabalho é compartilhado entre esses dois espaços. Assim, a cidade em si, caracteriza-se por concentrar as atividades dos setores secundário e terciário, além disso, comumente remete ao moderno e ao tempo rápido. Já o campo está associado às atividades primárias e ao tempo lento. Contudo, cada vez mais essa dicotomia tem se diluído, e é perceptível observar mesmo nas grandes cidades espaços imbricados, em que se verificam tanto aspectos característicos do urbano, quanto característicos do rural.No campo, temos visto o aparecimento de atividades que reproduzem práticas tipicamente rurais a partir da lógica urbana. É o caso do turismo rural, em que se emprega um modo de vida rural como estratégia de mercado. Outra atividade é a ampliação do mercado imobiliário, em que se utiliza o campo para a construção de condomínios rurais para segundas residências.

Com o desenvolvimento da técnica e, por conseguinte, com a modernização da agricultura, áreas agrícolas vêm sendo dominadas por novos aparatos técnicos e por novas lógicas de produção. No Brasil, sobretudo a partir da década de 1950, a incorporação de tecnologias e a modernização no campo, redefiniram as relações cidade-campo. Desde então, observa-se o que alguns autores denominam de “modernização agrícola conservadora”. Esse termo se refere às características da modernização agrícola no Brasil, que ocorreu associando a entrada de inovações tecnológicas no campo com a manutenção e ampliação da concentração e da especulação fundiária pelos grandes proprietários rurais. Esse fato expulsou muitos pequenos agricultores do campo, forçando-os a migrarem para as cidades.Pois, sem terem condições de competir com os grandes produtores e manterem sua produção, tiveram como saída procurar na cidade melhorias de vida. Assim, alocados nas cidades, nas mais diversas condições, muitos mantiveram práticas originarias do campo, por "necessidade" ou por “desejo"(MAIA, 1994).

A relação cidade-campo pode ser entendida a partir de várias abordagens, dentre elas destacam-se: “a urbanização do campo" em que os estudos compreendem essa 
relação levando em consideração a expansão da cidade e da urbanização em direção ao campo, onde este passa a ter um incremento de atividades industriais, de setores de fornecimento de insumos e de atividades voltadas ao turismo; já outros estudiosos fazem um percurso contrário buscando entender essa relação refletindo a partir das atividades e práticas rurais presentes na malha urbana das cidades. É de acordo com esta última postura que pretendemos analisar os "subespaços rurais" encontrados no perímetro urbano de Campina Grande, tentando compreender como se dá a sua permanência e a sua (re) produção nessa cidade.

O interesse por estudar as práticas rurais na cidade de Campina Grande surgiu devido às observações realizadas nas margens da malha urbana e nos bairros periféricos, onde frequentemente começamos a nos deparar com currais, vacarias, pocilgas, áreas não edificadas sendo utilizados como área para pasto de gado na cidade, além de pequenas plantações agrícolas e criações de aves domésticas. Esses elementos geralmente localizados em bairros ou áreas afastadas do núcleo central, próximos às habitações das camadas populares, chamaram nossa atenção e nos fizeram pensar sobre os motivos pelos quais as pessoas trabalhavam com a produção de leite e carne para o consumo próprio e/ou para a comercialização na cidade. Por isso, resolvemos estudar a relação cidade-campo e começamos a nos perguntar por que essas pessoas mantinham tais práticas em espaços tão urbanizados, onde dificilmente é possível mantê-las.

Com o intuito de compreendermos a existência de práticas rurais na cidade de Campina Grande, investigamos como elas têm sido reproduzidas, quem são as pessoas que realizam as atividades rurais, como mantêm essas práticas rurais e quais as características e as condições das áreas que são utilizadas. Esses aspectos foram essenciais para nossa análise, e a fim de conseguir respostas para eles, fizemos vários trabalhos de campo, observações e entrevistas.

Devido ao fato de as práticas rurais acontecerem, principalmente, nas margens da malha urbana, iniciamos a observação pela área de expansão da cidade. Em um dos primeiros trabalhos de campo, andamos ao longo de toda a alça sudoeste ${ }^{3}$, observando, fotografando e verificando as atividades rurais produtivas existentes nas bordas dessa rodovia. Em seguida, adentramos em direção ao interior do tecido urbano, visando encontrar pequenas ocupações e estabelecimentos rurais, onde a prática rural, na maioria das vezes, é realizada como uma forma de ajudar na alimentação e na 
permanência das pessoas na cidade. Para localizar as áreas com características rurais na cidade, utilizamos como ferramenta o levantamento de imagens de satélite, como, por exemplo, as do programa Google Earth, cuja análise foi fundamental para orientar os percursos realizados nos trabalhos de campo pela cidade.

A partir dos trabalhos de campo, selecionamos uma área delimitada - localizada abaixo da rede de alta tensão da Companhia Hidroelétrica do São Francisco (CHESF) como objeto para a análise. Assim, nessa área, focalizamos os trabalhos de campo, as entrevistas e os registros fotográficos. A rede de alta tensão atravessa, no sentido nortesul, a parte oeste da cidade de Campina Grande e percorre os seguintes bairros: Novo Bodocongó, Serrotão, Ramadinha, Malvinas, Três Irmãs, Presidente Médice, Acácio Figueiredo e Velame.

É importante ressaltar que foram entrevistadas 14 pessoas. Procuramos entrevistar todas as pessoas que mantêm atividades rurais debaixo da linha de transmissão de energia da CHESF; no entanto, nem todas se disponibilizaram, por medo ou por vergonha. Contudo, as conversas informais com elas também foram essenciais para as análises aqui realizadas. O número 14 refere-se apenas àquelas pessoas que se dispuseram a ser entrevistadas e nos deixaram gravar as suas falas.

As áreas localizadas abaixo da rede de alta tensão, nas quais foram encontrados vários estábulos e pessoas praticando atividades rurais, caracterizam-se como áreas públicas, impróprias para ocupação e voltadas para o uso restrito da CHESF. Apesar disso, são ocupadas por pessoas que detêm posses e a utilizam para manter algumas práticas rurais, como criações de gado bovino, equino ou suíno e plantações agrícolas. Também descobrimos pessoas que, além de criar alguns animais, mantêm-se com sua comercialização.

Dentre os aspectos que ressaltamos para a escolha dessa área da cidade, estão: a localização, pois se encontra nos interstícios da cidade, e um dos aspectos importantes da pesquisa foi enfatizar a apropriação de espaços "vazios" para a realização de práticas rurais; a característica específica da área, porque a maioria das pessoas não são proprietárias dos terrenos, e sim, possuem pequenas posses, já que o terreno é público e é proibido ocupar a área; e a prática das atividades e o cotidiano das pessoas, que consistem em pequenas criações de gado (bovino, equino e suíno) e plantações agrícolas voltadas para o próprio consumo e/ou para a comercialização na cidade. 
Entendemos que a área situada sob a rede de alta tensão em Campina Grande, por se encontrar dentro de sua malha urbana, corresponde, diretamente, aos questionamentos que buscamos solucionar em relação ao motivo da existência de práticas rurais em áreas tão urbanizadas. Logo, ao enfatizar a apropriação da cidade por meio da realização de atividades próprias do campo, resolvemos escolher a área sob a rede de alta tensão, em contraposição às restantes, sobretudo porque a maioria das demais áreas volta-se para a expansão urbana, onde a contraposição entre as práticas rurais e as urbanas não são tão evidenciadas.

\section{A apropriação do rural na cidade}

Sabemos que a cidade consiste num local concentrado, em que as pessoas vivenciam uma rotina diária muito corrida, motivada pela realização de atividades controladas pela lógica urbana e impostas pelo horário do relógio e do trabalho. Além disso, a produção da cidade ocorre de maneira racionalizada, e para cada área é atribuído um determinado uso, conforme os interesses dos governantes e dos grupos dominantes. Contudo, queremos mostrar que, na cidade, também existem áreas onde as atividades e os usos não condizem com essa realidade citadina.

Ainda que seja comum, as instituições públicas não considerarem a existência de atividades rurais dentro do perímetro urbano, encontramos em muitas cidades brasileiras a prática de atividades agropecuárias e a permanência de hábitos característicos do campo. Em Campina Grande, não é diferente, ao andar pela cidade, podemos nos surpreender ao ver várias paisagens que retratam um modo de vida do campo: pessoas cavalgando pelas ruas; carroças sendo utilizadas para transportar alimento do gado; animais pastando em vazantes; estabelecimentos como currais, cocheiras e chiqueiros; pessoas cuidando do gado ou tirando leite de vacas; plantações de capim; resquícios de antigas fazendas; pessoas adestrando cavalos; etc.

É interessante destacar que essas paisagens revelam áreas localizadas dentro do perímetro urbano que em grande parte, ficam encobertas pelas construções da cidade. Com base nas andanças e nos trabalhos de campo exploratório, verificamos que existem muitas criações de gado e plantações em Campina Grande. Algumas dessas atividades estão localizadas em propriedades privadas na área de expansão urbana, no entanto, 
existem várias criações de gado e pequenas plantações sendo mantidas na área, predominantemente residencial, sobretudo, onde se instalou a rede de alta tensão.

A área coberta pela rede de alta tensão é uma delas e abrange uma superfície inadequada para edificação e ocupação urbana. No entanto, em Campina Grande,em vários trechos abaixo da rede de alta tensão, visualizamos atividades que passam despercebidas no cotidiano da maioria dos moradores da cidade, porque tais atividades consistem em práticas espaciais não características da cidade, mas da realidade e do cotidiano vivenciado no modo de vida rural. A atividade rural que, inicialmente, chamanos a atenção, na paisagem da área investigada, é a criação de gado. Entretanto, entre as criações, vimos pequenas plantações de milho, feijão, frutas e verduras compondo pequenos sítios. Existem também pequenos criadores que vivem da comercialização de animais como porcos, jumentos e cavalos - esses dois últimos são utilizados frequentemente como tração para carroças.

Encontramos muitas pessoas que mantêm atividades rurais, não apenas pela necessidade econômica, pois, embora algumas realmente necessitem da renda a partir do gado (bovino, equino ou suíno) para o próprio sustento e o da família, há muitas outras aposentadas que criam ou plantam devido ao desejo de permanecer vivenciando um cotidiano do campo, já que, de modo geral, são migrantes da área rural de outros municípios ou moram em antigos terrenos rurais que foram incorporados à malha urbana. Assim, o que ambos, aposentados ou não, têm em comum é o prazer nas atividades e nos hábitos próprios do campo.

Se levarmos em consideração os lotes estabelecidos na cidade, a área que se encontra sob a rede de alta tensão abrange uma ampla superfície não edificada. Dessa maneira, algumas pessoas encontraram nesse local a possibilidade de manter tais atividades, apropriando-se e delimitando a área em pequenas posses, mantendo "ilhotas de ruralidade" (LEFEBVRE, 2001) ou "subespaços rurais" (MAIA, 1994) na cidade. Para entendermos o porquê da permanência de atividades e hábitos rurais encontrados na cidade de Campina Grande, utilizamos o conceito de "espaço vivido" elaborado por Lefebvre e utilizado por alguns geógrafos, entre eles, Damiani (2008) e Maia (2000). Esse conceito compõe a tríade: "espaço concebido, espaço vivido e espaço percebido". É por meio desses conceitos que o autor explica os momentos contraditórios existentes na produção social do espaço. 
Fundamentamo-nos em Lefebvre (1991), por entendermos o espaço concebido como sendo aquele construído pelas estratégias econômicas e políticas, em que governantes e administradores elaboram modelos abstratos, distantes do real e reguladores das práticas sociais; já o espaço percebido consiste nas representações elaboradas por meio da percepção da produção social do espaço; e o espaço vivido é o que, conforme Damiani (2008) é “o espaço que os habitantes produzem, apesar da redução das relações diretas, implicada nas formas modernas do espaço concebido. Este é o plano das práticas espaciais" (2008, p. 88).

Com essa citação, esclarecemos que as práticas rurais encontradas sob a rede de alta tensão, em Campina Grande, não são produzidas de maneira legalizada nem levadas em consideração no planejamento da cidade, mas realizadas com base nas necessidades cotidianas e por um modo de fazer e de pensar que se contrapõem à lógica de produção que ali existe. Portanto, as áreas que mantêm atividades rurais na cidade se constituem como um "espaço vivido", pois ocorrem devido à "apropriação" da cidade, que é planejada e concebida como um lugar inadequado para o desenvolvimento de atividades agropecuárias, logo, voltada para a produção industrial, a concentração, o mercado, etc.

$\mathrm{E}$ as pessoas que se apropriam da cidade e se mantêm basicamente da realização de atividades características do modo de vida rural conservam costumes que são considerados atrasados pela maioria dos citadinos, como, por exemplo, utilizar animais e carroças de tração como meio de transporte, ordenhar o gado manualmente, vender o leite in natura pelas ruas, etc. Esses costumes rurais, geralmente, contradizem a lógica urbana dominante na produção da cidade, a qual é produzida pelos governantes e pelos proprietários fundiários como "espaço concebido". 


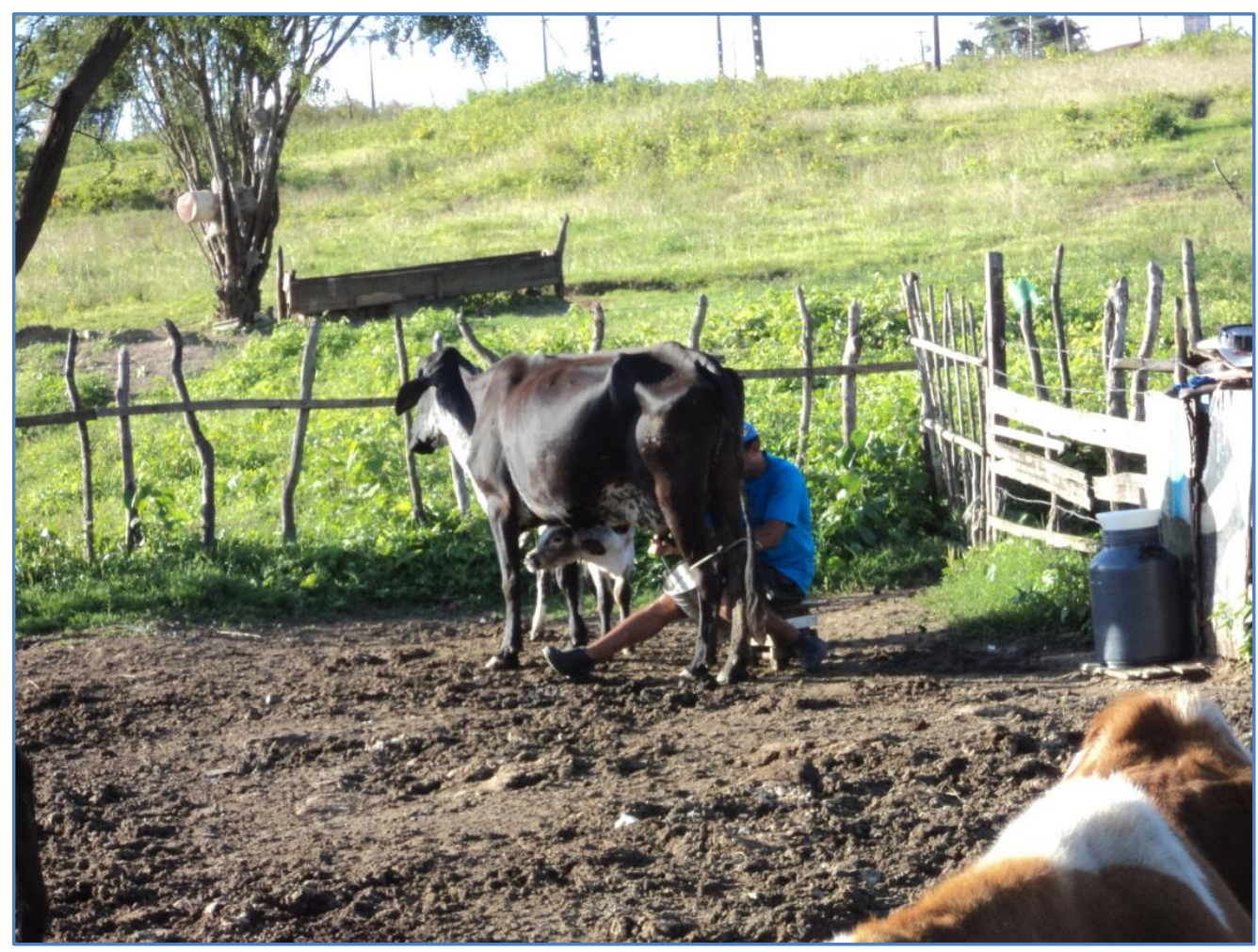

Foto 1: Criador de gado realizando a ordenha no final da tarde no Bairro Malvinas.

Fonte: Trabalho de Campo, agosto de 2012. Foto: Sonale Vasconcelos de Souza.

Certeau (1994) destaca que o poder dominante, exercido pela modernidade científica, política ou militar, delimita para cada prática social um "lugar próprio" de realização, ou seja, para cada atividade, é atribuído um espaço apropriado e delimitado. Assim, podemos pensar na cidade e no campo, respectivamente, como áreas voltadas separadamente para a realização de atividades urbanas e rurais. No entanto, o autor mencionado lembra que, no estudo das práticas sociais, não é tão simples classificá-las ou delimitá-las, pois existem as "modalidades da ação". Em outros momentos, Certeau (1994) também chama de "maneiras de fazer ou estilos de ação"os diferentes usos realizados sobre determinado espaço (cidade, rua, etc.) ou sistema de representação (língua, meios de comunicação, etc.).

Entendemos, então, a cidade como um espaço regulamentado para as práticas urbanas. Contudo, destacamos que é necessário verificar, em determinadas áreas, práticas cotidianas que podem ser consideradas "estilos de ação" diferentes daqueles relacionados à cidade, a exemplo das atividades agropecuárias. Essas maneiras de fazer 
e de produzir na cidade revelam um uso e uma forma de vivenciar o tempo e o espaço muito divergente da maneira predominante de viver na cidade.

Com base nos escritos de Certeau (1994), entendemos as práticas cotidianas realizadas nos subespaços rurais como "maneiras de fazer", realizadas por pessoas que desejam manter um modo de vida rural na cidade. Essas pessoas, de alguma forma, acabam contornando a ordem imposta à cidade, já que esse espaço é apenas planejado e voltado para a realização de atividades urbanas e não compreende a priori a prática de atividades rurais. Certeau (1994) propõe dois conceitos, com o intuito de analisar as práticas cotidianas: "estratégias" e "táticas". Para esse autor, a estratégia é

$$
\begin{aligned}
& \text { o cálculo (ou a manipulação) das relações de forças que se torna possível a } \\
& \text { partir do momento em que um sujeito de querer e poder (uma empresa, um } \\
& \text { exército, uma cidade, uma instituição científica) pode ser isolado. A } \\
& \text { estratégia postula um lugar suscetível de ser circunscrito como algo próprio e } \\
& \text { ser a base de onde se podem gerir as relações com uma exterioridade de alvos } \\
& \text { ou ameaças (os clientes ou os concorrentes, os inimigos, o campo em torno } \\
& \text { da cidade, os objetivos e objetos da pesquisa, etc.). (CERTEAU, 1994, p. 99) }
\end{aligned}
$$

Nesse sentido, as pessoas que detêm o poder sobre a cidade, ao planejar e controlar as áreas existentes nesse espaço, exercem estratégias de dominação. As estratégias consistem no poder de decidir e de exercer controle sobre determinado lugar, como o poder dos governantes e das classes dominantes que projetam, orientam e fiscalizam o crescimento da malha urbana. Tais agentes visam obter lucros a partir da especulação imobiliária de espaços não edificados. Ademais, procuram intimidar ou punir as pessoas que desrespeitam as normas ou princípios estabelecidos, inclusive as pessoas que fogem do padrão ideal para a cidade por realizar práticas consideradas "desviacionistas", como o uso de carroças puxadas à tração animal na cidade e a venda do leite in natura diretamente para a população.

Em contrapartida, conforme Certeau (1994, p. 100), a tática é "a ação calculada que é determinada pela ausência de um próprio. Então nenhuma delimitação de fora lhe fornece a condição de autonomia. A tática não tem por lugar senão o outro". Assim, relacionando ao nosso objeto de análise, podemos considerar como táticas as práticas cotidianas, plurais e criativas, encontradas pelas pessoas para conservar determinados costumes rurais na cidade. As táticas são caracterizadas por Certeau (1994) como a "arte do fraco", pois elas dependem da criatividade das pessoas e das circunstâncias do momento, já que tais pessoas não têm autonomia no espaço dominado pelas classes hegemônicas. 
Embora não tenham poder de decisão sobre a área urbana, as pessoas que mantêm atividades rurais em áreas citadinas apresentam um grande desejo de conservar determinados costumes rurais e não abrem mão do que gostam de fazer e do modo como gostam de viver, portanto, diariamente, lutam por sua sobrevivência na cidade, a partir de uma lógica contrária à empreendida nesse espaço.

Compreendemos, então, os subespaços rurais encontrados na cidade como espaços produzidos por meio de táticas, pois apresentam hábitos e atividades que não são próprios dos locais onde estão estabelecidos e porque são mantidos diante de adversidades existentes na cidade. Esses subespaços rurais, geralmente, apresentam-se como resíduos que são mantidos em áreas voltadas para a expansão urbana e em áreas não edificadas da cidade. Algumas dessas áreas urbanizadas não edificadas correspondem às áreas de proteção ambiental (vazantes de rios ou riachos), aos terrenos que estão à espera de valorização ou às áreas abaixo das linhas de alta tensão.

\section{Práticas ruraissoba rede de alta tensão: as criações de gado bovino}

A rede de alta tensão, dentro do perímetro urbano de Campina Grande, desdobra- se em 12 quilômetros e percorre, na direção norte-sul, parte de vários bairros da zona sudoeste como: Novo Bodocongó, Serrotão, Ramadinha, Malvinas, Três Irmãs, Presidente Médici, Acácio Figueiredo (conhecido por Catingueira) e Velame. Esses bairros, atualmente, localizados em áreas afastadas do centro da cidade, há trinta anos, na década de 1980, quando se intensificou o crescimento urbano, apresentavam características muito mais rurais que urbanas. Em várias entrevistas, verificamos que, no início da ocupação urbana, a paisagem rural era muito presente. Sobre esse momento, um dos nossos entrevistados comentou:

nós não era empregado de ninguém e se mantinha com o leitinho do gado,
né, tinha comida em todo canto, né, tinha capoeira em todo canto, hoje é tudo
tapado de casa, pronto, eu morei ali uns tempo, ali olhe, ali naquelas casas era
tudo roçado de mandioca, se plantava milho, feijão...aqui mesmo também
era, da feira da Prata pra cá tudo era roçado, isso em 1964 tudo era roçado, da
Prata pra aqui o povo tudo trabalhava nos quadros de terra, era tudo roçado
aqui. Aqui, nas Malvinas era sítio, não tinha rua, não, tá rua agora. (Sr.
Gentil, 28/05/2012)

Além disso, a instalação das torres e da rede de alta tensão, no final da década de 1950, foi anterior à expansão da malha urbana na área, uma vez que abrangeu antigas 
propriedades rurais. Tais informações nos ajudam a compreender a permanência de resquícios de antigas fazendas e sítios na área investigada em meio à cidade construída. No entanto, não encontramos apenas resíduos de propriedades rurais, pois também é muito significativa a apropriação de terrenos para a realização de atividades agropecuárias na área investigada. Isso ocorre, entre outros fatores, devido às condições favoráveis no local: área não edificada e terrenos com presença de vazantes. Portanto, a área aberta sem edificação e o terreno encharcado propiciam a criação de animais devido ao crescimento e à manutenção do pasto - fonte básica utilizada para alimentar o gado - ea plantação de culturas regionais.

Ao longo da rede de alta tensão, deparamo-nos com diversas paisagens rurais; algumas são vestígios de fazendas e de sítios que se mantiveram mesmo com o crescimento da malha urbana. Esses estabelecimentos rurais permaneceram aproveitando as sobras de terras entre os loteamentos e a linha de alta tensão; já outras paisagens são recriações de atividades rurais, que são adaptadas aos terrenos debaixo da rede de alta tensão, sob a qual, nos bairros mais adensados e edificados - Ramadinha e Malvinas - predominam paisagens com atividades que se caracterizam como recriações rurais. 
Mapa 1 - Atividades rurais identificadas sob a rede de energia da CHESF

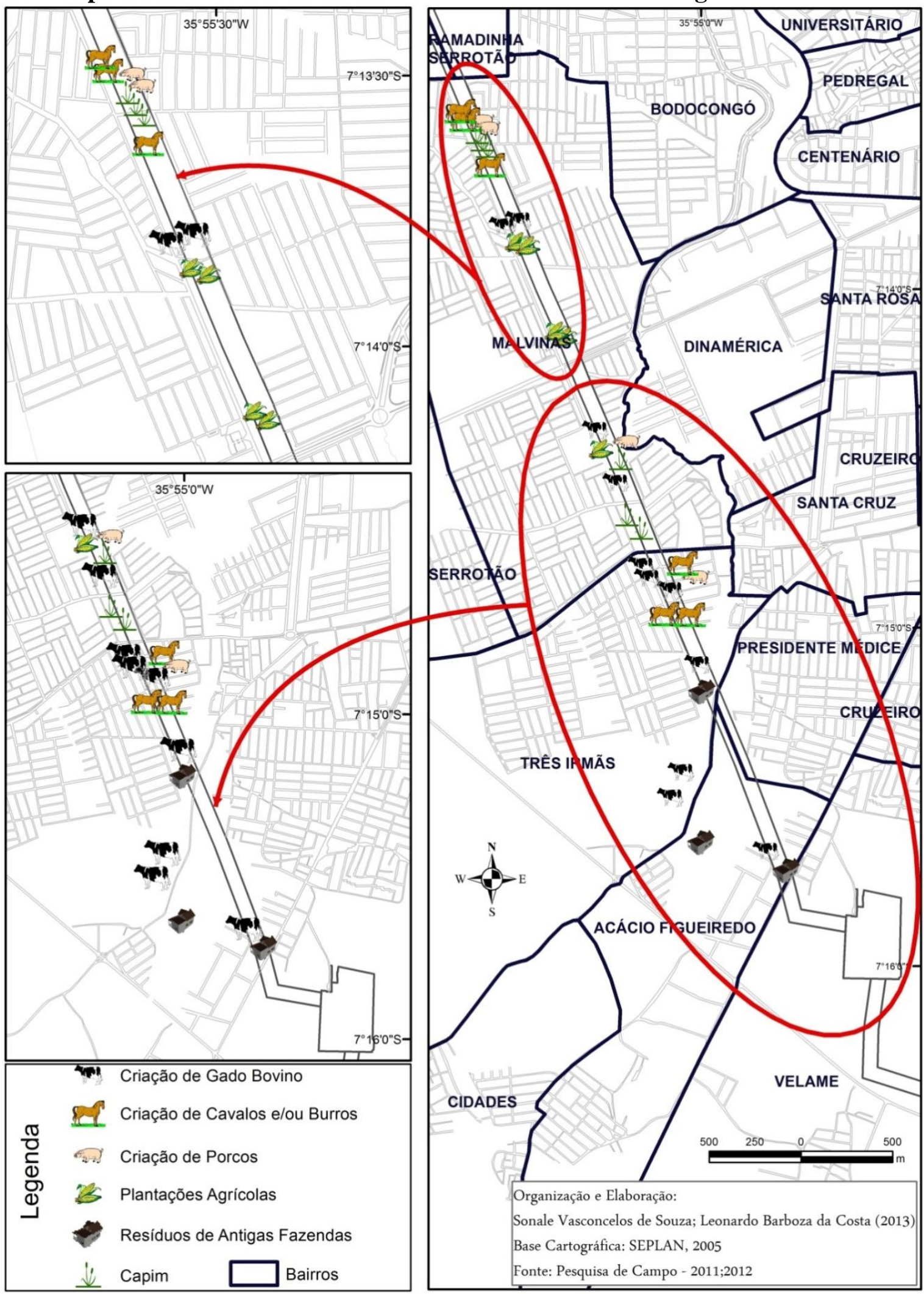

*OBS: Com relação à simbologia utilizada no mapa, é importante destacar que cada animal representa um criador de gado ou um estabelecimento pecuário, cada milho indica um agricultor e cada planta verde significa uma área com plantação de capim que geralmente é utilizada para alimentar o gado.

Geo UERJ - Ano 15, nº 24, v. 2, $2^{\circ}$ semestre de 2013

ISSN: 1415-7543E-ISSN: 1981-9021

http://www.e-publicacoes.uerj.br/index.php/geouerj 
Assim, ao longo da área coberta pela rede de alta tensão, durante os trabalhos de campo, identificamos e mapeamos várias atividades, a saber: criação de gado bovino, de animais utilizados para cavalgar e como tração e de suínos, além de pequenas plantações agrícolas (mapa 1). É interessante enfatizar que essas atividades rurais são mantidas na cidade devido às necessidades econômicas e/ou ao desejo das pessoas de realizá-las. Contudo, embora algumas pessoas sobrevivam da produção rural na cidade, praticamente todas elas as mantêm pela vontade de realizá-las, por prazer ou para manter um costume.No entanto, neste artigo desvendaremos apenas as criações de gado, pois essa atividade é predominante na área investigada - debaixo da rede de alta tensão.

O gado bovino é criado em sobras de antigas propriedades rurais ou em pequenas posses delimitadas sob a rede de alta tensão. Os terrenos onde existem criações de gado variam bastante de tamanho, no entanto, aqueles referentes às propriedades rurais são maiores, têm cerca de 3 a 5 hectares. É interessante destacar que há duas propriedades rurais sob a rede de alta tensão com áreas que ultrapassam esses números. Uma delas, segundo informações dadas pelos empregados do proprietário, tem uma área de, aproximadamente, 30 hectares e, frequentemente, recebe propostas de pessoas interessadas em comprá-la; a outra está localizada entre as instalações da CHESF e o aeroporto, em uma área onde a ocupação urbana não pode ser adensada. As demais criações se dão em pequenas áreas, que variam em torno de 1 hectare. Embora ocupem terrenos menores, elas têm um número maior de estabelecimentos na cidade. 


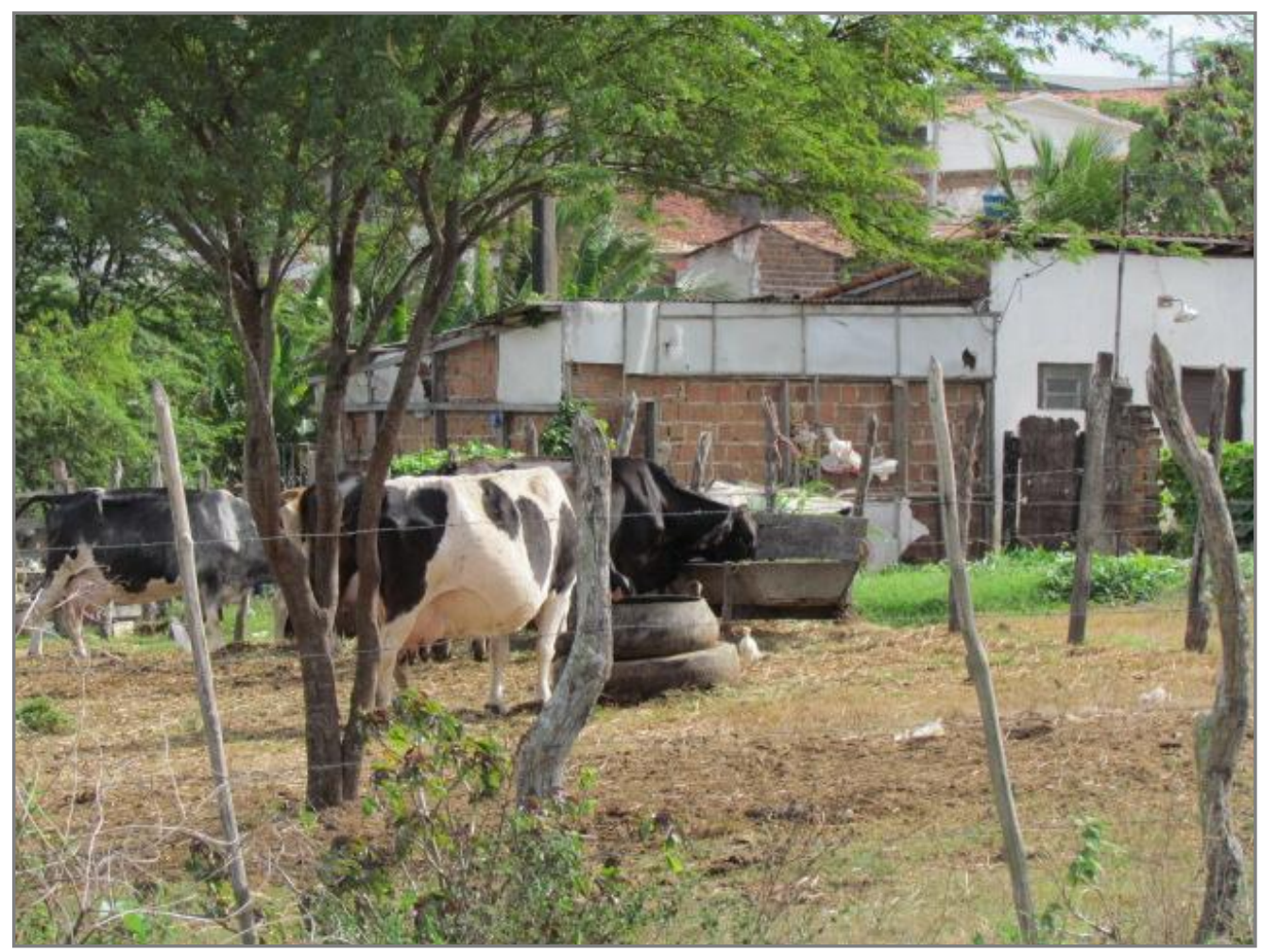

Foto 2 - Curral sem cobertura localizado ao lado da Rua dos Avelozes no Bairro Malvinas.

Fonte: Trabalho de campo, janeiro de 2012. Foto: Sonale Vasconcelos de Souza.

Excetuando-se as duas propriedades maiores apontadas anteriormente, que apresentam maior área e, por conseguinte, rebanho superior a 100 animais, as criações têm em torno de 20 cabeças de gado, incluindo vacas, bois e bezerros. $\mathrm{O}$ curral é a instalação básica utilizada nessas criações de gado, pois, é nele onde os animais passam a maior parte do tempo, saindo apenas para pastar durante o dia. Além disso, alguns criadores alimentam o gado no próprio curral e, dificilmente, levam o gado para pastar. É por isso que a maioria dos entrevistados afirmou criar o gado num "hotel", apontando o fato de cuidar do gado preso como uma das principais dificuldades para manter essa atividade na cidade, pois, fora o fato de a alimentação ser bem dispendiosa, esses criadores estão acostumados com a pecuária extensiva que realizavam antes na zona rural. 


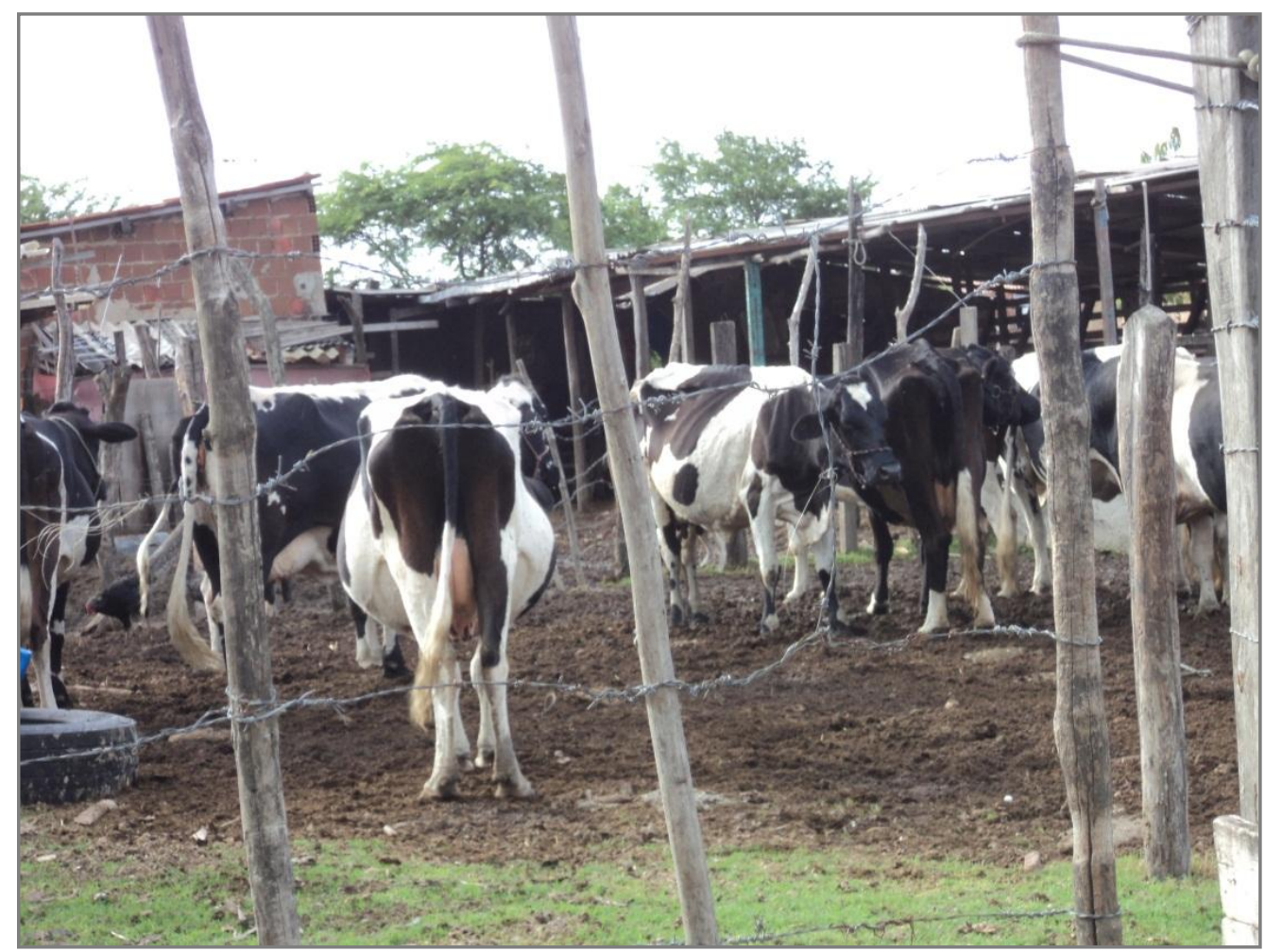

Foto3 - Curral ao lado da moradia do criador, numa posse localizada no Bairro Três Irmãs.

Fonte: Trabalho de campo, maio de 2012. Foto: Sonale Vasconcelos de Souza.

Os currais encontrados consistem numa estrutura simples, semelhante àquelas encontradas na zona rural; são construídos com pau a pique; ora formam uma única dependência ora são divididos e têm uma manjedoura que, na maioria das vezes, é amparada pela sombra de alguma árvore (Foto2), já que, na área, não pode ser edificada nenhuma estrutura. Todavia, evidenciamos alguns currais com uma parte coberta, como o da foto3. Nesse caso, os currais, quase sempre, estão juntos da moradia dos criadores.

$\mathrm{Na}$ área investigada, embora as atividades rurais representem fonte de renda, as pessoas não criam gado apenas pela necessidade econômica, mas o principal motivo para manterem essa prática é o desejo de trabalhar fazendo o que gostam e que aprenderam desde criança. Por meio das entrevistas, percebemos que, praticamente, a maioria dessas pessoas, em algum momento, já trabalhou ou ainda trabalha em outras atividades na cidade. Contudo, apesar de morar na cidade e exercer atividades urbanas, elas nunca abandonaram o gosto pela vida rural. Alguns entrevistados disseram que já chegaram a criar gado no fundo do quintal de suas moradias. É o que expressa o Sr. Antônio: "Trabalhei 5 anos de barbeiro pra completar a feira dos meninos, trabalhava de 
pedreiro, de barbeiro e criava gado, toda vida eu criei no quintal da casa, ali na Rosa Cruz eu criava duas vacas no quintal da casa, pra ter o leite dos meninos [...]" (Sr. Antônio, 01/08/2012).

Também podemos observar, nas palavras do Sr. Genival, a vontade de trabalhar criando gado, pois, mesmo exercendo a profissão de motorista para sustentar a família, ele sempre manteve o gado:

\begin{abstract}
Sempre criei gado, a herança que meu pai deixou foi essa, desde pequeno eu sempre vivi nessa vida, morava no sítio aí vim pra aqui, aí daqui eu aprendi a profissão de motorista, aí já não quis mais ir pro sítio, né, aí fiquei trabalhando de carreteiro, né, aí eu fiquei trabalhando de carreta um bocado de tempo, aí não arrumei quem tomasse conta do gado, aí eu parei a carreta e vim tomar conta. Trabalhava em carreta dos outros, por que aqui tem que trabalhar pra manter o gado, por que a renda não dava pra manter o gado, agora não, por que agora eu tenho umas vacas de leite mais ou menos, né, e estou me mantendo do leite, tem que dar pra elas e pra mim um pouquinho também, eu mantenho a casa com elas. (Sr. Genival, 30/05/2012)
\end{abstract}

Em sua fala, Sr. Genival afirma que sua única renda é a venda do leite de gado e que já chegou a vender leite in natura nas portas das residências, mas alguns consumidores pagavam e outros, não, por isso, deixou essa prática. Atualmente, esse criador vende apenas ao leiteiro, que pega em sua própria casa. E embora o preço do leite seja mais barato, ele diz que o leiteiro paga em dia. Nesse caso, o leiteiro é um atravessador que revende o leite aos estabelecimentos na cidade, como padarias, mercadinhos e supermercados.

Apesar de ser proibida desde a década de $1970^{4}$, a venda do leite in natura pelas ruas da cidade era uma prática muito comum. O próprio criador vendia o leite em carroças ou bicicletas, no entanto, hoje essa prática já é mais difícil de ser vista. O que ainda pode ser evidenciado é a venda ou a doação desse leite em pequena quantidade para a vizinhança, como podemos visualizar na foto4. Os entrevistados que têm a produção do leite como uma das fontes de renda, geralmente, realizam duas ordenhas por dia, uma pela manhã e outra à tarde. Contudo, como o número de vacas é pequeno, a produção de leite varia, diariamente, em torno de dois litros por vaca. Há aqueles que, além de criar gado leiteiro, vivem da comercialização do gado de corte e frequentam constantemente as feiras de gado. 


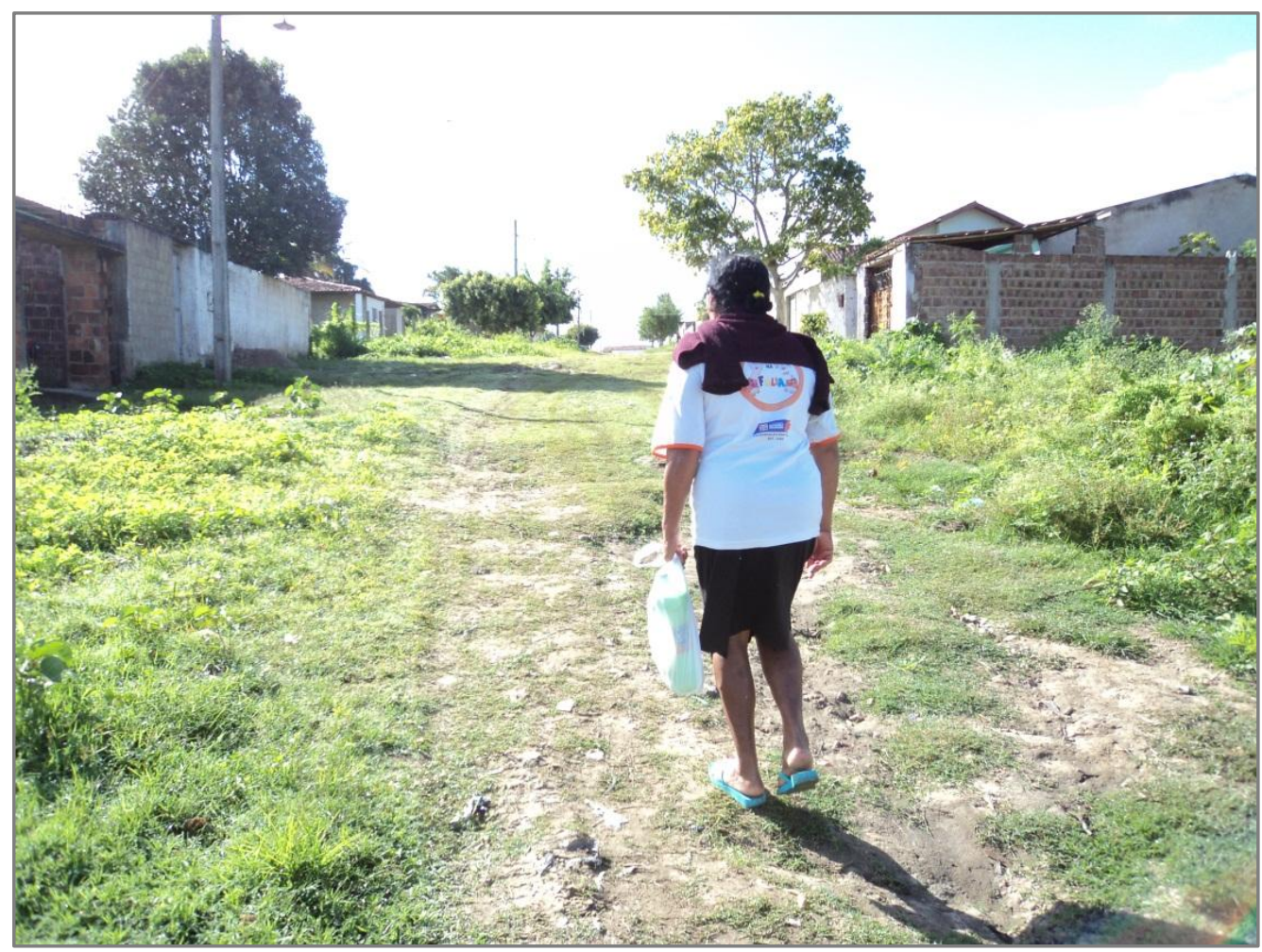

Foto4 - Moradora antiga do Bairro Presidente Médici, que mantém, no quintal de casa, pequenos roçados e um curral de gado bovino. Ela está levando leite in natura numa garrafa pet para a vizinha.

Fonte: Trabalho de campo, agosto de 2012. Foto: Sonale Vasconcelos de Souza.

A investigação acerca dos criadores de gado bovino também nos mostrou que existe, em alguns casos, a associação da criação de gado (leiteiro ou de corte) a outras atividades, ou seja, alguns produtores criam o gado e utilizam o que é produzido em outra atividade desenvolvida por eles mesmos. É o caso de um criador de gado que, além de criar, comercializa e tem um açougue próximo de casa; outro exemplo é o de uma proprietária, que tem uma criação de gado e utiliza o leite para a fabricação de pamonhas. Além desses, como vimos a partir das falas do Sr. Antônio e do Sr. Genival, existem aqueles que moram na cidade, trabalham em atividades urbanas (de motorista, vigilante, pedreiro, comerciante, etc.) e mantêm a criação de gado. 


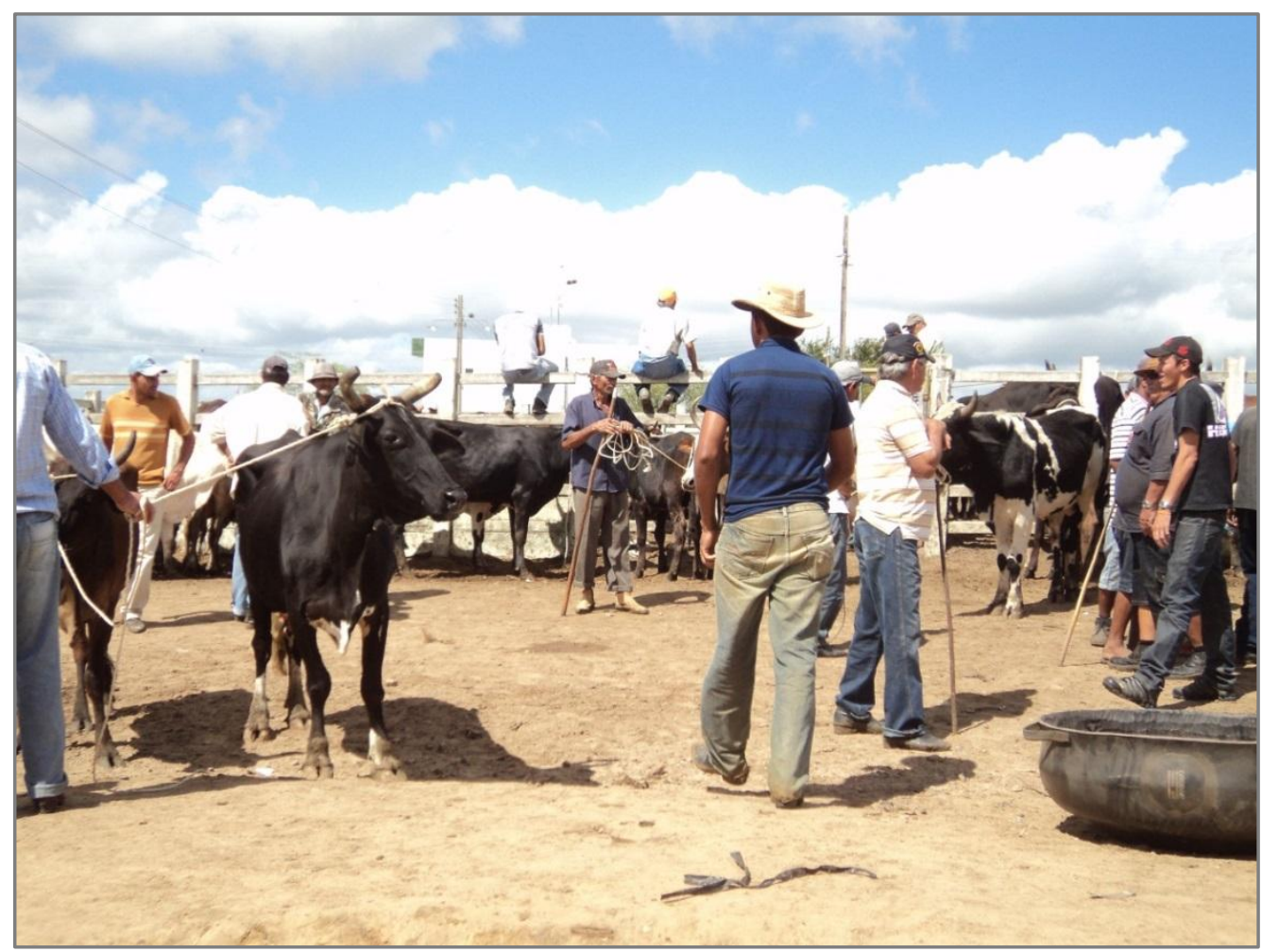

Foto5 - Feira de gado de Campina Grande, realizada às quartas-feiras no Parque de Exposição Carlos Pessoa Filho.

Fonte: Trabalho de campo, agosto de 2012. Foto: Sonale Vasconcelos de Souza.

Supomos que a divisão do tempo de trabalho com outras atividades ocorre porque a criação de gado é muito onerosa, sobretudo na cidade, já que o gado é criado preso, como os entrevistados falam num "hotel". Assim, embora o capim das vazantes ajude na alimentação, os criadores disseram que é necessário acrescentar outras fontes de alimento, por isso, alguns afirmaram trabalhar para manter o gado. Na fala do Sr. Genival, fica explícito um pouco dessa dificuldade de criar o gado na cidade:

[...] a gente compra palma e torta também, farelo, saco de milho pra besta, é tudo pago, aqui só tem de graça um capimzinho de uma vagem que eu tenho, o resto é tudo pago [...] As desvantagens é que aqui é tudo pago, né, e o leite é barato, né, o leite é muito barato, a gente vende o leite aqui a 0,80 centavo, pra manter um moi de gado desse é trocando leite por comida pra eles, e o que sobra pra gente é muito pouco [...] É isso mesmo uns deixam por causa da despesa que é grande, um caminhão de palma é 600 real, aqui eu gasto um todo mês, aí vem a torta que agora aumentou pra 57, um saco, quer dizer, eu dou três saco por semana aqui, então, já vai mais de 165 real, aí vem o milho, eu sei que a despesa é grande e é por que eu não tenho empregado [...](Sr. Genival, 30/05/2012)

Podemos observar, nessa fala, que o produtor relata não ter empregado para auxiliá-lo.Apesar de a maioria dos criadores não empregarem pessoas, existem alguns 
que contratam um ou dois ajudantes, mesmo que temporariamente, para fazer determinados serviços, como pegar capim nas vazantes para alimentar o gado e consertar uma cerca. Nesses casos, o salário e os serviços são combinados entre o proprietário e o trabalhador. Geralmente, os trabalhadores não têm a carteira assinada e recebem por mês um salário mínimo e dois litros de leite por dia.

Todos os criadores de gado entrevistados viveram, durante a infância, em propriedades rurais de Campina Grande ou de municípios das regiões do Agreste paraibano e da Borborema - Alagoa Nova, Areia, Esperança, Fagundes, Ingá, Barra de Santana, Monteiro, São João do Cariri, Riachão do Bacamarte - onde aprenderam a cuidar de animais e a trabalhar na agricultura com os pais, ainda muito pequenos. Logo, mesmo tendo vindo para a cidade por motivos diversos, não conseguiram deixar a vontade e o gosto pelo modo de vida rural. Assim, compreendemos que a criação de gado, na cidade, acontece devido ao desejo de trabalhar com essa atividade e à manutenção de um costume. Percebemos isso quando os criadores dizem que, apesar das situações adversas, nunca deixaram e nem deixarão de criar gado.

Ao questionarmos sobre as desvantagens de manter a atividade pecuária na cidade, os entrevistados destacaram dois pontos principais: o primeiro refere-se à alimentação que é muita cara; e o segundo está relacionado à expansão da malha urbana que diminuiu/diminui cada vez mais as áreas de pasto dos animais. No entanto, os criadores que têm pequenas criações em áreas de posse apropriadas ou adquiridas, debaixo da linha de transmissão de energia, dão ênfase às dificuldades em relação aos gastos com a alimentação do gado, pois esses produtores já estão acostumados, de certo modo, a criar os animais presos em "hotéis" (currais). Muitos até já criaram em outros momentos no quintal de casa. 


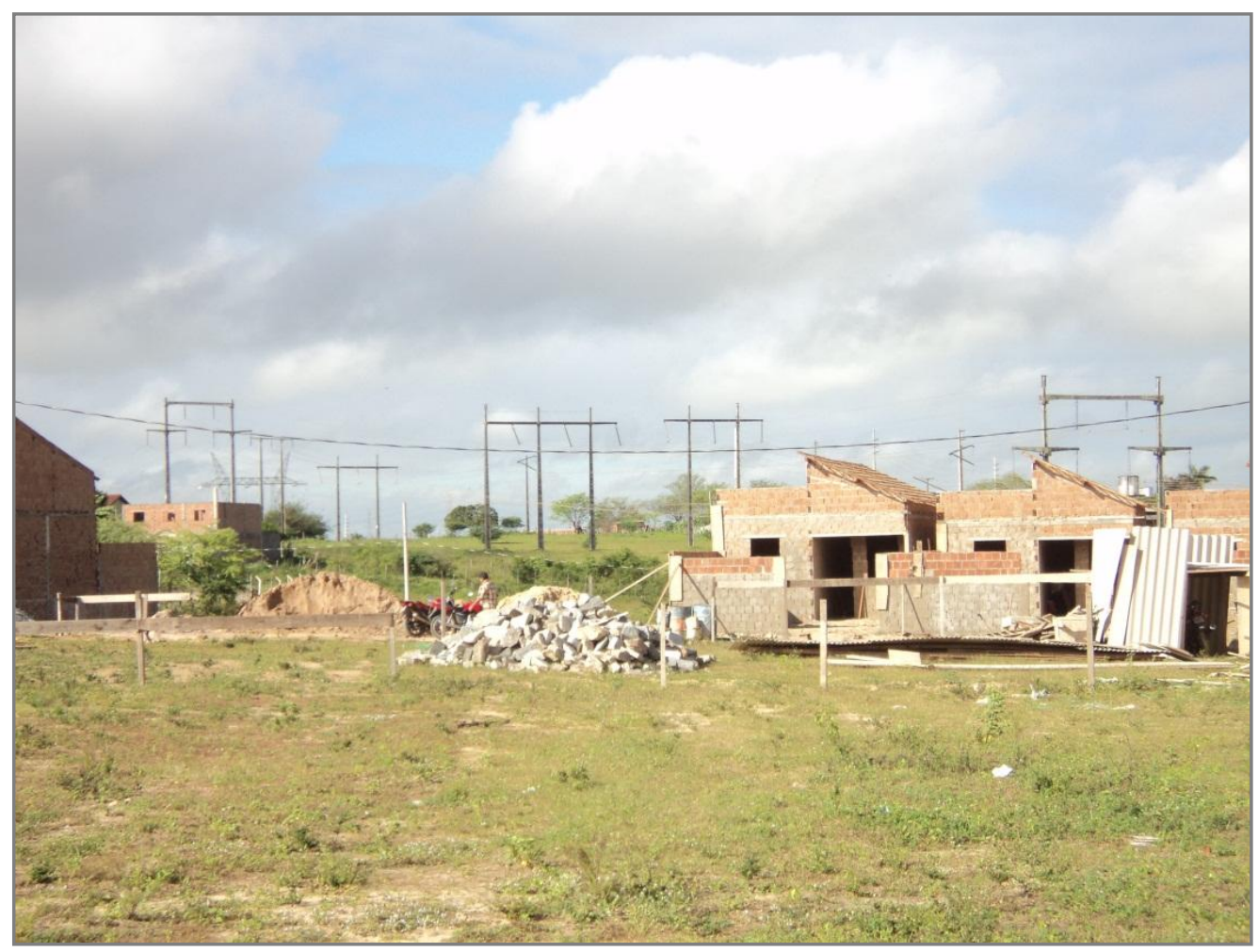

Foto6 - Loteamento e moradias sendo construídas entre a rede de alta tensão e a malha urbana, no Bairro Acácio Figueiredo, aproveitando espaços não edificados que restaram de antigas propriedades rurais.

Fonte: Trabalho de campo, agosto de 2012. Foto: Sonale Vasconcelos de Souza.

Já aqueles que criam gado em sobras de antigas propriedades rurais, também localizadas sob a rede de alta tensão, ressaltam o crescimento da cidade e das edificações como o principal obstáculo para continuar cuidando do gado na cidade (Foto6). Entrevistamos um vaqueiro - o Sr. Jaime - que trabalhava para um fazendeiro numa dessas propriedades que foram "engolidas" pela cidade. Atualmente, ele ainda se mantém no que sobrou da propriedade - uma área com cerca de 5 hectares - vivendo da criação de gado bovino e de outros animais que são comercializados na cidade - como porcos e galinhas - além de cuidar de alguns cavalos cujos proprietários participam de vaquejadas. Durante a entrevista, ele falou:

Na cidade, hoje, não tá dando mais não, aqui pra gente, por que futuramente aqui vai ser casa de um canto a outro, aí fica apertado demais, vou ter que deslocar ou partir pra outro destino, pra outro ramo, né, procurar outra viração, porque essa aqui, a gente tá por enquanto aqui, mas se a qualquer momento os herdeiros for vender aqui a parte que der pra construir, eu vou ter que ir, porque aí eu não vou ter local pra criar nada, né, até mesmo uma galinha fica difícil de criar. [...]Às vezes a pessoa deixa né nem pelo abandono, vontade tem, é por que não tem condição mais de o cabra manter, entendeu, por que quem tinha uma terra por aqui perto e criava antes, hoje,

Geo UERJ - Ano 15, n' ${ }^{\circ}$ 24, v. 2, $2^{\circ}$ semestre de 2013

ISSN: 1415-7543E-ISSN: 1981-9021

http://www.e-publicacoes.uerj.br/index.php/geouerj 
ele não pode criar mais, vai criar longe, nos Cariris, os Cariris é bruto, né, numa época seca dessa todo mundo sofre, né isso, tem muitos criador aí que deixou de criar. (Sr. Jaime, 30/05/2012)

Essa fala esclarece a dificuldade que os criadores de gado enfrentam para manter a atividade pecuária na cidade devido à ampliação da infraestrutura e das construções urbanas. Até por volta dos anos 1960, o núcleo urbano de Campina Grande era concentrado e compacto, e a malha urbana crescia lentamente e de modo disperso. $\mathrm{Na}$ área periférica da cidade e nas proximidades da linha de transmissão de energia da CHESF, havia muitas fazendas, sítios e roçados. Atualmente, os terrenos não edificados localizados nessa área estão sendo loteados, e a infraestrutura urbana está sendo ampliada, portanto, cada vez mais é difícil e custoso criar o gado. Em contrapartida, todas as pessoas, sem exceção, durante as entrevistas, afirmaram que pretendiam continuar com a criação de gado porque gostavam dessa atividade.

Com base no exposto e no que refletimos a partir dos trabalhos de campo, chegamos à conclusão de que esses criadores não se veem fazendo outra coisa, pois afirmam que "a lida com o gado", aprendida ainda na infância com os pais, é a atividade que lhes dá satisfação. Assim, embora alguns, em determinado momento, tenham desempenhado funções urbanas, não esqueceram e não abandonaram a prática, o costume característico do modo de vida rural, apesar de alterações e adaptações à vida na cidade. Uma dessas adaptações ou alterações é o uso do tempo.

Assim como Maia (2000), também notamos que o uso do tempo ocorre de modo peculiar pelos que se dedicam às atividades rurais. Logo, para os criadores de gado, o dia a dia é marcado pelo sol e para eles não existem feriados ou "dias de descanso", pois acordam cedo todos os dias e passam o dia todo cuidando do gado. Portanto, obedecem sempre à mesma rotina. Tal fato é destacado pelos próprios criadores, como pode ser visto nas seguintes falas:

"Minha rotina aqui é de 5 horas, eu já começo o movimento, passo o dia todo... Nos finais de semana, é a mesma rotina, só trabalho, dificilmente sai quem cuida dessas coisas, meu tempo é curto.” (Jaime, 30/05/2012);

"É 5 horas da manhã ele já está acordado, ele passa o dia aqui trabalhando, atucalha no pasto, leva pra capoeira, onde tiver um pasto bonzinho a gente tá procurando." (Dona Nadjair, esposa de Genival, 30/05/2012)

Contudo, eles falam sobre a rotina com muito prazer, dizem que é bom trabalhar por conta própria, que acordar cedo todos os dias não é nenhum sacrifício quando se está perto dos animais. Logo, para essas pessoas, lazer e trabalho se misturam, como 
fica evidente nas palavras de um dos entrevistados: "pra mim, a minha vida, vamos dizer assim, o trabalho e o lazer é dentro um do outro, é rodando" (Sr. Antônio, 01/08/2012).

\section{Considerações finais}

As observações e análises permitem afirmarmos que as atividades rurais existentes na área investigada são realizadas, principalmente, devido ao prazer proporcionado às pessoas que as mantêm. Essas pessoas de modo geral vivenciaram o campo na sua infância e aprenderam com seus pais e avós a desenvolver as atividades rurais. A metade dos entrevistados é aposentada e afirmaram manter as atividades rurais por que sentem a necessidade de vivenciá-las cotidianamente, sempre dizem que gostam e não sabem ficar sem trabalhar. Esses aposentados durante a vida economicamente ativa trabalharam em profissões urbanas, contudo, a maioria disse que mesmo não sobrevivendo da pecuária ou da agricultura, sempre teve e dividiu seu tempo com alguma produção rural na cidade.

A outra metade que ainda está trabalhando, afirma manter as atividades rurais tanto pelo prazer em realizá-las como pela necessidade econômica. Alguns dependem unicamente da produção do leite e da criação de gado, embora, já tenham desempenhado outras atividades na cidade, não conseguiram abandonar o modo de vida rural, por isso resolveram investir e sobreviverem a partir dessa atividade. Entretanto, existem pessoas que adaptaram o modo de vida rural à cidade ao associar atividades rurais com atividades urbanas.

Desse modo, verificamos pessoas que criam gado e utilizam o leite na produção de alimentos que são revendidos nos estabelecimentos da cidade, como também, pessoas que criam gado de corte e possuem um estabelecimento comercial - como, por exemplo, um açougue, neste caso, o gado é vendido a outros comerciantes ou é abatido para ser vendido no açougue. Além disso, há famílias em que os homens assumem a responsabilidade de cuidar da criação de gado e comercializá-la, em contrapartida, as mulheres complementam a renda desenvolvendo outras atividades ou serviços, como o conserto de roupas e a fabricação e a comercialização de alimentos. 
Destarte, as criações de gado realizadas na área coberta pela rede de alta tensão, conforme nossas reflexões podem ser entendidas a partir dos conceitos apresentados por Lefebvre (1991, 2008): apropriação e espaço vivido. Pois, essas atividades rurais têm sido praticadas em uma área urbana delimitada e planejada apenas para ter a rede de energia de alta tensão, sendo nessa área proibida a ocupação e a construção de qualquer edificação por menor que seja como, por exemplo, pequenos currais com cobertura. Embora a área seja inadequada para a construção de edificações e para a realização de atividades urbanas, as pessoas têm se apropriado para desenvolver as atividades rurais, a apropriação se dá na vivência das pessoas nessa área, as atividades rurais são realizadas não porque elas não têm outra opção, mas porque se sentem satisfeitas com o cotidiano rural.

Lefebvre (1991) afirma que o espaço apropriado assemelha-se a uma obra de arte, não no sentido de imitação de uma obra de arte, mas no sentido do vivido, logo, a obra de arte consiste num produto da sensação vivenciada pelo artista no momento de sua construção, ou seja, movida pela necessidade do artista de expressar algo que está sentindo. Do mesmo modo os "subespaços rurais", encontrados sob a rede de alta tensão, são espaços construídos por pessoas que sentem a necessidade e a satisfação em viver a partir das atividades e do modo de vida rural.

\section{Notas de rodapé}

1 Este escrito consiste em parte da pesquisa "Relação cidade-campo: permanência e recriação dos subespaços rurais na cidade de Campina Grande-PB” desenvolvida no Programa de Pós-Graduação em Geografia sob a orientação da Prof ${ }^{a}$. Doralice Sátyro Maia.

${ }^{2}$ Subespaços rurais foi um termo proposto por Maia (1994) para definir as áreas com atividades rurais encontradas no perímetro urbano de João Pessoa-PB. Em sua pesquisa, a autora verificou que os subespaços rurais se localizavam, principalmente, nas margens dos rios que cortam essa cidade.

${ }^{3}$ A alça sudoeste é uma via rodoviária criada com o intuito de imprimir mais rapidez ao tráfego de veículos vindos do litoral paraibano e do agreste pernambucano, ambos com destino ao Sertão, a Curimataú e ao Cariri paraibano. Esta estrada com, aproximadamente, $12 \mathrm{~km}$ de extensão, margeia a cidade de Campina Grande e une as rodovias BR104 (sul) e BR230(oeste).

${ }^{4}$ Desde a década de 1950, por meio da Lei Federal $\mathbf{N}^{\mathbf{0}} \mathbf{1 . 2 8 3 / 5 0}$ e do Decreto $\mathrm{N}^{\mathbf{0}}$ 30.691/52, o leite, assim como os outros produtos de origem animal, comestíveis ou não comestíveis, são obrigados a passar periodicamente por fiscalizações sanitárias. Além disso, a partir da década de 1970 o Decreto $\mathrm{N}^{\circ}$ $66.183 / 70$ determina que seja proibido em todo o território nacional a venda do leite cru ou in natura para consumo direto da população. 


\section{Referências}

CÂNDIDO, Antônio. Os parceiros do Rio Bonito: estudo sobre o caipira paulista e a transformação dos seus meios de vida. Rio de Janeiro: Ouro sobre azul, 2010.

CERTEAU, Michel de. A invenção do cotidiano: artes de fazer. Petrópolis: Vozes, 1994.

DAMIANI, Amélia Luisa. Espaço e Geografia: Observações de Método - Elementos da obra de Henri Lefebvre e a Geografia; - Ensaio sobre Geografia Urbana a partir da Metrópole de São Paulo. 2008. 414 f. (Tese de Livre-Docência em Geografia Urbana) - Faculdade de Filosofia, Letras e Ciências Humanas, Universidade de São Paulo, São Paulo, Agosto de 2008.

LEFEBVRE, Henri. De lo rural a lo urbano: antologia preparada por Mario Gaviria. $4^{\text {a }}$ ed. Barcelona: EdicionesPenínsula, 1978. p. 268.

LEFEBVRE, Henri. The production of space.Oxford: Blackwell Publishing, 1991.p. 454.

LEFEBVRE, Henri. Espaço e Política. Belo Horizonte: Editora UFMG, 2008.

MAIA, Doralice Sátyro.Hábitos rurais em vidas urbanas. In: Amélia Luísa Damiani; Ana Fani Alessandri Carlos; Odette Carvalho de Lima Seabra. (Org.). O espaço no fim do século: a nova raridade. $1^{a}$ ed. São Paulo: Contexto, 1999. p. 214-220.

MAIA, Doralice Sátyro. O campo na cidade: necessidade e desejo (Um estudo sobre subespaços rurais em João Pessoa-PB). 1994. 208 f. Dissertação (Mestrado) - Área de concentração: Desenvolvimento Regional e Urbano, Universidade Federal de Santa Catarina, Florianópolis, 15 de dezembro de 1994.

MAIA, Doralice Sátyro. Tempos lentos na cidade: permanências e transformações dos costumes rurais na cidade de João Pessoa-PB. 2000. $364 \mathrm{f}$. Tese (Doutorado em Geografia Humana) - Universidade de São Paulo, São Paulo.

SOUZA, Charles Benedito Gemaque. A contribuição de Henri Lefebvre para reflexão do espaço urbano da Amazônia. Confins [Online], 5| 2009, posto online em 20 Março 2009, Consultado o 24 Janeiro 2012. URL: http://confins.revues.org/5633 ; DOI : 10.4000/confins.5633

Artigo recebido para publicação em maio de 2013.

Artigo aceito para publicação em julho de 2013. 